\title{
Angiotensin enzyme inhibitors and angiotensin receptor blockers as protective factors in COVID-19 mortality: a retrospective cohort study
}

\author{
Ashkan Yahyavi ${ }^{1} \cdot$ Nima Hemmati $^{1} \cdot$ Pegah Derakhshan $^{1} \cdot$ Behrooz Banivaheb $^{1} \cdot$ Arman Karimi Behnagh ${ }^{1}$. \\ Rozhin Tofighi ${ }^{1} \cdot$ Alireza TehraniYazdi $^{2} \cdot$ Ali Kabir $^{1}$ (I)
}

Received: 27 May 2020 / Accepted: 29 September 2020 / Published online: 21 October 2020

(c) Società Italiana di Medicina Interna (SIMI) 2020

\begin{abstract}
Targeting the renin-angiotensin system is proposed to affect mortality due to coronavirus disease 2019 (COVID-19). We aimed to compare the mortality rates in COVID-19 patients who received angiotensin-converting enzyme inhibitors or angiotensin receptor blockers (ACEIs/ARBs) and those who did not. In this retrospective cohort study, mortality was considered as the main outcome measure. All underlying diseases were assessed by the chronic use of medications related to each condition. We defined two main groups based on the ACEIs/ARBs administration. A logistic regression model was designed to define independent predictors of mortality as well as a Cox regression analysis. In total, 2553 patients were included in this study. The mortality frequency was higher in patients with a history of underlying diseases $(22.4 \%$ vs $12.7 \%$, $P$ value $<0.001)$. The mortality rate in patients who received ACEIs/ARBs were higher than non-receivers $(29.3 \%$ vs. $19.5 \%$, $P$ value $=0.013, \mathrm{OR}=1.3,95 \% \mathrm{CI} 1.1,1.7)$ in the univariate analysis. However, the use of ACEIs/ARBs was a protective factor against mortality in the model when adjusted for underlying conditions, length of stay, age, gender, and ICU admission $(P$ value $<0.001, \mathrm{OR}=0.5,95 \%$ CI $0.3,0.7)$. The Kaplan-Meier curve showed an overall survival of approximately $85.7 \%$ after a 120-day follow-up. ACEIs/ARBs are protective factors against mortality in COVID-19 patients with HTN, and these agents can be considered potential therapeutic options in this disease. The survival probability is higher in ACEIs/ ARBs receivers than non-receivers.
\end{abstract}

Keywords Angiotensin-converting enzyme inhibitors (ACEIs) · Angiotensin receptor antagonists · COVID-19 · SARS$\mathrm{CoV}-2 \cdot$ Hypertension $\cdot$ Mortality $\cdot$ Renin-angiotensin system $\cdot$ Survival analysis

\section{Introduction}

As of September 21st, more than 30,000,000 cases of coronavirus disease 2019 (COVID-19) and more than 900,000 deaths have been reported [1]. A considerable number of victims have pre-existing comorbidities: hypertension (HTN) (30\%), diabetes mellitus (DM) (20\%), coronary artery disease (CAD) (6\%), and vascular diseases of the

Ali Kabir

aikabir@yahoo.com; kabir.a@iumc.ac.ir

1 Minimally Invasive Surgery Research Centre (MISRC), Iran University of Medical Sciences (IUMS), Rasoul-e Akram Hospital, Mansouri Alley, Niyayesh St., Sattarkhan St., Tehran, Iran

2 Department of Energy Engineering and Physics, Amirkabir University of Technology, Tehran, Iran central nervous system $(3 \%)[2,3]$. Many of the patients suffering from such comorbidities receive the renin-angiotensin system (RAS) inhibitors to regulate blood pressure.

Until now, no specific medication is available for the treatment of COVID-19, and the current guidelines are focused on reducing the probability of transmission by enforcing physical distancing, isolation, and supportive interventions in positive cases [4]. Several medications have been proposed, one of which is based on targeting the angiotensin-converting enzyme 2 (ACE2) receptor with special recombinant molecules [5].

Studies have revealed that based on the biochemical and crystal structure of severe acute respiratory syndrome coronavirus (SARS-CoV), this virus's surface glycoprotein exhibits a high affinity for the human ACE2 receptor. Since the structural amino acid sequence of SARS-CoV-2 is $76.5 \%$ similar to its predecessor, SARS-CoV, the mentioned surface 
proteins are mostly homologous. However, further studies revealed that SARS-CoV-2 shows greater efficiency in binding to the ACE2 receptor than SARS-CoV, hence the former's higher virulence. This surface protein is essential for detection of and entry to the host cells [6, 7]. Overexpression of the ACE2 receptor was associated with aggravated disease in animal models and, by facilitating the virus's entry, it resulted in increased damage to the lung tissue. On the other hand, the inhibition of RAS, which is dependent on the ACE expression, results in the improvement of pulmonary symptoms, probably by increasing anti-inflammatory mediators [8]. Besides, a study on mice, revealed that the administration of RAS inhibitors is associated with reduced pulmonary inflammatory response and mortality [9].

Accordingly, it is inferred that the compromised pulmonary protection caused by the novel virus, is one of the reasons for the high mortality rate. The ACE2 receptor is expressed on the surface of different tissues, such as the intestinal lining, heart, lungs, kidneys, and liver [10, 11]. The vast distribution of ACE2 receptors on the surface of various types of cells throughout the body also explains the possible cause behind multi-organ failure in severe cases $[12,13]$. Targeting the ACE/angiotensin II/angiotensin I receptor (ACE/AngII/ATIR) is proposed as a novel management strategy in patients suffering from HTN. Angiotensin-converting enzyme inhibitors (ACEIs) and angiotensin receptor blockers (ARBs) are capable of targeting the ACE/ AngII/ATIR signaling pathway, as well as impacting the ACE/Ang receptor expression [14]. But it remains unknown if RAS inhibitors have clinical implications in COVID-19 treatment. Considering that the clinical effects of ACEIs/ ARBs on the outcome of COVID-19 are currently unclear, this study's primary objective is to compare the mortality rate in COVID-19 patients who received ACEIs/ARBs and those who did not.

\section{Methods}

In this retrospective cohort study, patients diagnosed with COVID-19 (according to World Health Organization interim guidance [15]), admitted to 17 referral hospitals affiliated to Iran University of medical sciences (IUMS) between February 20th and April 4th were enrolled. The main outcome measure in this study was considered mortality. The data were collected from the SEPAS system, a national integrated care electronic health record system [16]. The data gathering process is an automatic procedure. Whenever a patient is admitted to a hospital, the data (personal information, diagnosis, discharge information, all services, and administered medications) are captured in real-time. Since the least amount of human involvement is present in the data entry process, and a machine captures the data, it is reliable and consistent.

Eligibility criteria were: hospitalization due to COVID-19 and an age above 18 years. Recorded data included demographic variables, underlying comorbidities including DM, HTN, chronic kidney disease (CKD), chronic pulmonary diseases (CPD), malignancies, cardiovascular diseases (CVD), chronic use of immunosuppressive medications, intensive care unit (ICU) admission, length of hospital stay (LOS) and clinical outcomes (death/recovery). Patients were followed after discharge for at least 120 days. It should be mentioned that HTN was included as a subgroup of CVD. As of immunosuppressant medications, all patients who received any of the drugs in the following classes chronically were included: calcineurin inhibitors, anti-proliferative agents, mammalian target of rapamycin inhibitors, and steroids. Antihypertensive drugs were categorized into five groups: diuretics, calcium channel blockers (CCBs), beta-blockers, ACEIs, and ARBs. Based on national guidelines, the protocol for the treatment of COVID-19 is hydroxychloroquine plus a combination of lopinavir-ritonavir or ribavirin or oseltamivir based on the clinical opinion of admitting physician [17].

All underlying diseases were assessed by the chronic use of medications related to each condition. All the patients had a history of receiving these medications both before and during hospitalization. In this study, we defined two main groups based on the administration of ACEIs/ARBs; the receivers and non-receivers. All the cases who had a history of ICU admission were considered critically ill.

The medical ethics committee of IUMS approved this study under the code number of IR.IUMS.REC.1399.200.

\section{Statistical analysis}

Categorical variables were described as frequency rates and percentages, and continuous variables were described using mean and standard deviation (SD) or median and interquartile range (IQR) values with 25 th and 75th percentiles in the parenthesis. Continuous variables were compared using independent samples T-test when the data were normally distributed; on the other hand, the Mann-Whitney $U$ test was implemented if the data were non-parametric. Regarding categorical variables, proportions were compared using the $\chi^{2}$ test. However, if the data were limited, Fisher's exact test was performed. A logistic regression model was used to adjust the probable confounding variables. Mortality was considered the dependent variable, and each variable with a $P$ value less than 0.2 were entered in the model by using the "Enter method". Odds ratios (ORs) and 95\% confidence interval (95\%CI) were also reported. For survival analysis, a Cox regression model was used. Hazard ratios (HR) were calculated, and the Kaplan-Meier curve was also 
implemented to show the survival of ACEIs/ARBs receivers versus non-receivers.

All statistical analyses were performed using SPSS version 23 (SPSS Inc., Chicago, Illinois). The significance level for P-value was considered 0.05 .

\section{Results}

\section{Baseline characteristics}

Among 2553 patients, 1498 (58.7\%) were male, and participants' mean age was $58.1 \pm 17.9$ years. In total, 1569 $(61.5 \%)$ patients had a history of an underlying disease (still under treatment), and 984 (38.5\%) had no history of any underlying condition. The rate of underlying diseases including CVD, CKD, CPD, DM, malignancy, and chronic use of immunosuppressive medications were $36.9 \%, 9.1 \%$, $26.9 \%, 19.5 \%, 1.7 \%$, and $1.3 \%$, respectively. In cases with a history of underlying diseases, frequencies of each condition for CVD (including HTN) was 942 (60\%), CKD 233 (14.9\%), CPD 686 (43.7\%), DM 498 (31.7\%), malignancy 43 (2.7\%), chronic use of immunosuppressive medications 34 (2.2\%) and HTN 710 (45.3\%). Among all patients, 83 (3.3\%) received ACEIs, 444 (17.4\%) received ARBs, 189 (7.4\%) received beta-blockers, 265 (10.4\%) received CCBs, and for 57 (2.2\%) of patients, diuretics were prescribed. In total, 500 (19.6\%) received either ACEIs or ARBs. Twentyseven patients had a history of taking both ACEIs and ARBs, which was corrected during hospitalization to a prescription of one of these classes only. The median of LOS was 5 days, with an IQR of $5(3,8)$. The number of cases admitted to ICU and deceased patients was 1000 (39.2\%) and 478 (18.7\%), respectively. The median follow-up duration was 124 days, $\mathrm{IQR}=6(121,127)$.

\section{Univariate analysis}

The frequency of DM, ICU admission, and CPD was higher in ACEIs receivers. LOS and mean age were also higher in ACEIs receivers when excluding patients who received ARBs. The mortality was not significantly different between ACEIs receivers and non-receivers $(25.0 \%$ vs. $17.8 \%, P$ value $=0.165, \mathrm{OR}=1.5,95 \% \mathrm{CI} 0.8,2.8)$. The frequency of chronic use of immunosuppressants, DM, ICU admission, CKD, CPD, mortality (22.3\% vs. $17.8 \%, P$ value $=0.030$, $\mathrm{OR}=1.3,95 \% \mathrm{CI} 1.0,1.7)$ and gender was higher among ARBs receivers when excluding patients who received ACEIs. LOS and mean age were also higher in ARBs receivers than non-receivers (Table 1).

The rate of all underlying conditions was higher in ACEIs/ ARBs receivers except for malignancy $(P$ value $=0.348$ ) Receivers of ACEIs/ARBs had a higher mean age, and the frequency of male patients was higher in non-receivers. LOS, ICU admission rate, and concurrent use of other antihypertensive medications are also demonstrated in Table 1.

There was no significant difference between mortality of male and female patients $(P$ value $=0.056)$, but the mean age was significantly higher in deceased cases (Table 2 ). The use of all antihypertensive medications was found to be more frequent in deceased patients. The frequency of mortality was significantly higher in patients with a history of underlying conditions with the chronic use of immunosuppressants as the foremost risk factor for mortality (Table 2). Attributable mortality risks of CVD, CKD, CPD, DM, malignancy, chronic use of immunosuppressive medications, and HTN were calculated as $11.2 \%, 5.8 \%, 11.8 \%, 10.2 \%, 16.4 \%$, $46.9 \%$, and $9.9 \%$, respectively.

\section{Multivariable analysis}

A logistic regression model was designed with mortality as the dependent variable and ACEIs/ARBs administration, CVD, CKD, CPD, DM, malignancy, and chronic use of immunosuppressants, age, gender, ICU admission, LOS, CCBs, diuretics, and beta-blockers as independent variables. The variables which were entered in the model had a $P$ value of less than 0.2 in univariate analysis. All ORs were reduced after entering the model except for gender and malignancy. CVD and DM were not statistically significant in the model $(P$ value $>0.05)$ although they were significant in univariate analysis (CVD: $\mathrm{OR}=2.0,95 \%$ CI 1.6, 2.4, $P$ value $<0.001$ and DM: $\mathrm{OR}=1.8,95 \%$ CI $1.4,2.3, P$ value $<0.001$ ) Unlike the results of univariate analysis $(29.3 \%$ vs. $19.5 \%$, $P$ value $=0.013, \mathrm{OR}=1.3,95 \%$ CI $1.1,1.7)$, the administration of ACEIs/ARBs was shown to be a protective factor against mortality in the model $(P$ value $<0.001, \mathrm{OR}=0.5$, 95\% CI 0.3, 0.7). CKD, CVD, DM, and ICU admission were confounding ACEIs/ARBs administration in the model in a way that, after adjustment, ACEIs/ARBs administration became a protective factor (Table 3 ).

Cox regression and Kaplan-Meier survival analyses were performed. The event was considered as death due to COVID-19 and time as the duration of follow-up. All variables with a $P$ value of less than 0.2 in univariate analysis were entered into the model with a "backward conditional method". These variables included ACEIs/ARBs administration, CVD, CKD, CPD, DM, malignancy, chronic use of immunosuppressants, ICU admission, gender, age, CCBs, beta-blockers, and diuretics. CVD, CKD, beta-blockers, CCBs, and diuretics were omitted from the model in 5 consequent steps. The chronic use of immunosuppressants had the highest HR (HR=3.1, 95\% CI 2.0, 4.8, $P$ value $<0.001$ ). Patients with a history of ACEIs/ARBs administration had a lower risk of mortality than non-receivers $(\mathrm{HR}=0.7,95 \%$ CI $0.6,0.9, P$ value $=0.008$ ). In addition to the chronic 


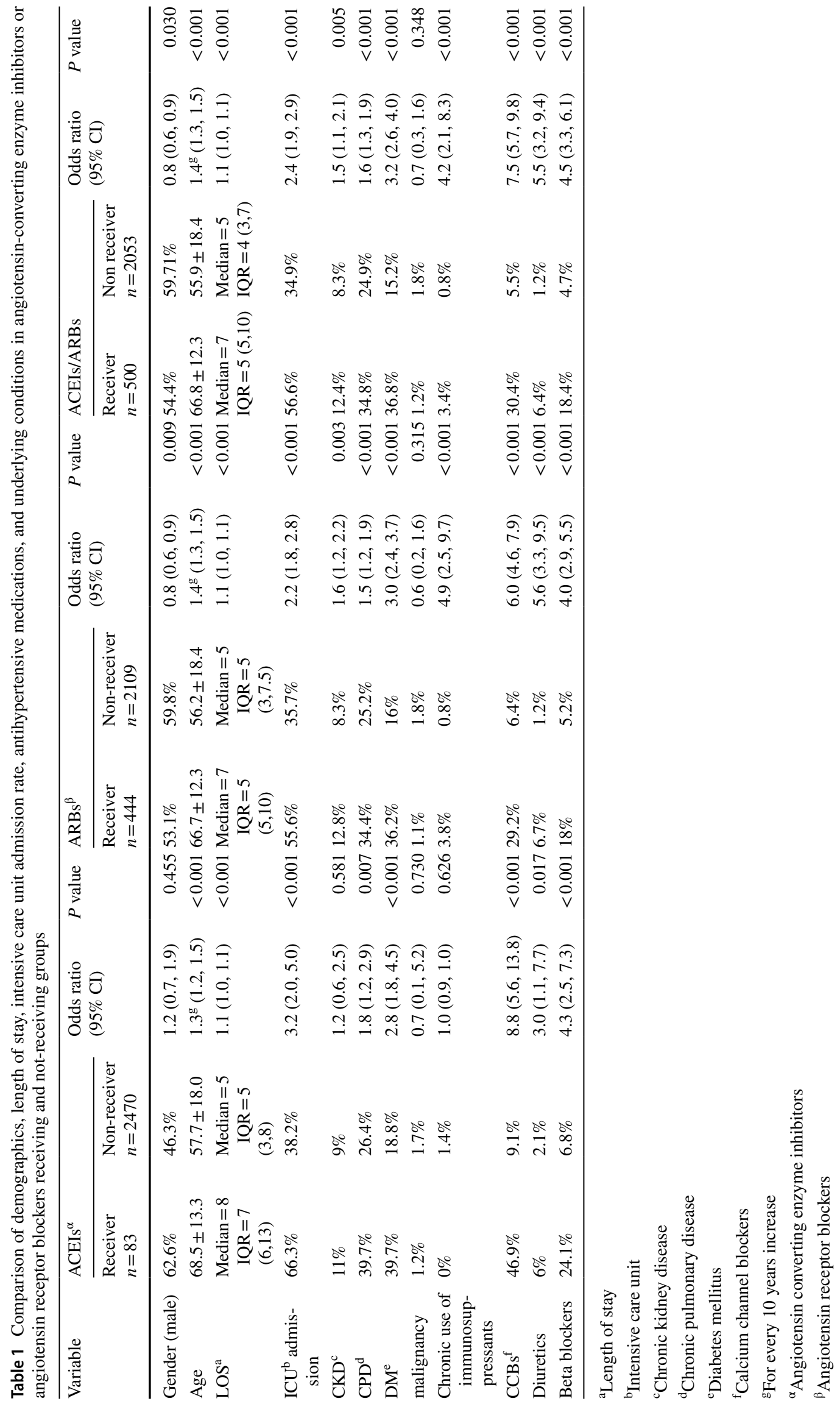


Table 2 Comparison of demographics, length of stay, intensive care unit admission rate, antihypertensive medications, and underlying conditions in deceased and survived COVID-19 patients

\begin{tabular}{|c|c|c|c|c|}
\hline \multirow[t]{2}{*}{ Variable } & \multicolumn{2}{|l|}{ Deceased } & \multirow[t]{2}{*}{ Odds ratio (\%95 CI) } & \multirow[t]{2}{*}{$P$ value } \\
\hline & $\begin{array}{l}\text { Yes } \\
n=478\end{array}$ & $\begin{array}{l}\text { No } \\
n=2075\end{array}$ & & \\
\hline Gender (male) & $62.5 \%$ & $57.7 \%$ & $1.2(0.9,1.5)$ & 0.056 \\
\hline Age & $68.9 \pm 15.6$ & $55.5 \pm 17.5$ & $1.5^{\mathrm{i}}(1.4,1.6)$ & $<0.001$ \\
\hline $\operatorname{LOS}^{\mathrm{a}}$ & $\begin{array}{l}\text { Median =6, } \\
\quad \mathrm{IQR}=7(3,10)\end{array}$ & $\begin{array}{l}\text { Median }=5 \\
\quad \mathrm{IQR}=5(3,8)\end{array}$ & $1.1(1.0,1.2)$ & $<0.001$ \\
\hline $\mathrm{ICU}^{\mathrm{b}}$ admission & $56.4 \%$ & $35.1 \%$ & $2.4(1.9,2.9)$ & $<0.001$ \\
\hline CVD & $50.8 \%$ & $33.6 \%$ & $2.0(1.6,2.5)$ & $<0.001$ \\
\hline $\mathrm{CKD}^{\mathrm{c}}$ & $11.7 \%$ & $8.5 \%$ & $1.4(1.0,1.9)$ & 0.029 \\
\hline $\mathrm{CPD}^{\mathrm{d}}$ & $39.3 \%$ & $24.0 \%$ & $2.0(1.6,2.5)$ & $<0.001$ \\
\hline $\mathrm{DM}^{\mathrm{e}}$ & $28.0 \%$ & $17.5 \%$ & $1.8(1.4,2.3)$ & $<0.001$ \\
\hline malignancy & $3.1 \%$ & $1.3 \%$ & $2.4(1.2,4.4)$ & 0.006 \\
\hline $\begin{array}{l}\text { Chronic use of immuno- } \\
\text { suppressants }\end{array}$ & $4.6 \%$ & $0.6 \%$ & $8.3(4.0,16.9)$ & $<0.001$ \\
\hline $\mathrm{CCB}^{\mathrm{f}}$ & $17.3 \%$ & $8.7 \%$ & $2.2(1.6,2.9)$ & $<0.001$ \\
\hline Diuretics & $4.6 \%$ & $3.2 \%$ & $2.8(1.6,4.8)$ & $<0.001$ \\
\hline Beta blockers & $12.1 \%$ & $6.3 \%$ & $2.0(1.5,2.8)$ & $<0.001$ \\
\hline HTN & $38.7 \%$ & $25.5 \%$ & $1.8(1.5,2.3)$ & $<0.001$ \\
\hline ACEIs ${ }^{\mathrm{g}} / \mathrm{ARBs}^{\mathrm{h}}$ & $23.6 \%$ & $18.6 \%$ & $1.3(1.0,1.7)$ & 0.013 \\
\hline \multicolumn{5}{|l|}{${ }^{\mathrm{a}}$ Length of stay } \\
\hline \multicolumn{5}{|l|}{${ }^{\mathrm{b}}$ Intensive care unit } \\
\hline \multicolumn{5}{|l|}{${ }^{\mathrm{c}}$ Chronic kidney disease } \\
\hline \multicolumn{5}{|c|}{${ }^{\mathrm{d}}$ Chronic pulmonary disease } \\
\hline \multicolumn{5}{|l|}{${ }^{\mathrm{e}}$ Diabetes mellitus } \\
\hline \multicolumn{5}{|l|}{${ }^{\mathrm{f}}$ Calcium channel blockers } \\
\hline \multicolumn{5}{|c|}{${ }^{\mathrm{g}}$ Angiotensin converting enzyme inhibitors } \\
\hline \multicolumn{5}{|c|}{${ }^{\mathrm{h}}$ Angiotensin receptor blockers } \\
\hline${ }^{\mathrm{i}}$ For every 10 years increa & & & & \\
\hline
\end{tabular}

use of immunosuppressants, a history of CPD and malignancy along with age and ICU admission were statistically significant in the Cox regression model (Table 4). The Kaplan-Meier curve showed a survival rate of $98.0 \%$, $92.7 \%, 86.4 \%$, and $85.7 \%$ in all patients recorded at 3rd, $7 \mathrm{th}, 26 \mathrm{th}$ days, and at the end of the study, respectively. The survival curve of ACEIs/ARBs receivers and non-receivers is demonstrated in Fig. 1.

\section{Discussion}

Among 2553 cases, $61.4 \%$ had a history of at least one underlying condition. Mean age, ICU admission rate, LOS, and mortality rate were higher in this group than patients without underlying disease. The most common underlying condition was CVD, followed by HTN, CPD, and DM.

There is still much controversy on whether taking ACEIs or ARBs are protective or risk factors of mortality in COVID-19. ACEIs and ARBs have been compared to a double-edged sword. It is claimed that the SARS CoV-2 virus has a high affinity to ACE2 and employs this molecule as an entry pathway to its target cells. In one pathophysiologic view taking ACEIs and ARBs upregulates ACE2 expression and provides more opportunity for the virus to enter host cells [18]. On the other hand, several studies suggest that ACE2 has an anti-inflammatory and protective effect, especially on the respiratory system, by changing angiotensin II to angiotensin (1-7). In this view, the administration of ACEIs/ARBs could help the respiratory system to respond more efficiently to the infection with SARS-CoV2 [19].

Several studies on SARS-COV and Middle East respiratory syndrome coronavirus showed that ACE2 receptors would downregulate due to interaction with the virus [20], the opposite of what would happen after ACEIs/ARBs administration. As a result of this virus-induced ACE2 downregulation, angiotensin (1-7) formation is reduced with consequent accumulation of angiotensin II. The excessive angiotensin II levels would favor pulmonary edema and inflammation, directly associated with angiotensin II levels. ARBs on the other hand, blocked such effects in some experimental models [21]. 
Table 3 The logistic regression model for prediction of mortality

\begin{tabular}{lllr}
\hline Variable & Unadjusted $\mathrm{OR}^{\mathrm{i}}\left(95 \% \mathrm{CI}^{\mathrm{f}}\right)$ & Adjusted OR $(95 \% \mathrm{CI})$ & P-value \\
\hline ACEIs $^{\mathrm{a}} / \mathrm{ARBs}^{\mathrm{b}}$ & $1.3(1.1,1.7)$ & $0.5(0.4,0.7)$ & $<0.001$ \\
$\mathrm{CVD}^{\mathrm{c}}$ & $2.0(1.7,2.5)$ & $1.1(0.8,1.5)$ & 0.480 \\
$\mathrm{CKD}^{\mathrm{d}}$ & $1.4(1.0,1.9)$ & $1.1(0.7,1.5)$ & 0.658 \\
$\mathrm{CPD}^{\mathrm{e}}$ & $2.0(1.7,2.5)$ & $1.8(1.4,2.2)$ & $<0.001$ \\
$\mathrm{DM}^{\mathrm{g}}$ & $1.8(1.5,2.3)$ & $1.3(1.0,1.6)$ & 0.073 \\
Malignancy $_{\text {Chronic use of immunosuppressants }}$ & $2.4(1.2,4.5)$ & $2.7(1.3,5.3)$ & 0.005 \\
Gender & $1.3(4.1,16.9)$ & $7.5(3.3,16.7)$ & $<0.001$ \\
Age & $1.2(1.0,1.5)$ & $1.2(1.0,1.6)$ & 0.049 \\
LOS & $1.5^{\mathrm{j}}(1.4,1.6)$ & $1.5 \mathrm{j}(1.4,1.6)$ & $<0.001$ \\
ICU & $1.03(1.01,1.05)$ & 0.002 \\
Diuretics & $1.07(1.05,1.09)$ & $1.7(1.3,2.1)$ & $<0.001$ \\
Beta-blockers & $2.4(1.9,2.9)$ & $1.3(0.7,2.5)$ & 0.392 \\
Calcium channel blockers & $2.8(1.6,4.8)$ & $1.2(0.8,1.8)$ & 0.302 \\
\hline
\end{tabular}

Model is adjusted for angiotensin-converting enzyme inhibitors, angiotensin receptor blockers, cardiovascular disease, chronic kidney disease, chronic pulmonary disease, diabetes mellitus, intensive care unit, diuretics, beta-blockers, and calcium channel blockers

${ }^{a}$ Angiotensin-converting enzyme inhibitors

${ }^{\mathrm{b}}$ Angiotensin receptor blockers

${ }^{\mathrm{c}}$ Cardiovascular disease

${ }^{\mathrm{d}}$ Chronic kidney disease

${ }^{\mathrm{e}}$ Chronic pulmonary disease

${ }^{\mathrm{f}}$ Confidence interval

${ }^{g}$ Diabetes mellitus

${ }^{\mathrm{h}}$ Intensive care unit

${ }^{i}$ Odds ratio

${ }^{\mathrm{j}}$ For every 10 years increase
Table 4 The Cox regression model for estimating independent variables in prediction of time of death due to COVID-19

\begin{tabular}{lllr}
\hline Variable & $\mathrm{HR}^{\pi}$ & $95 \% \mathrm{CI}^{\mathrm{d}}$ & $P$ value \\
\hline ACEIs $^{\mathrm{a}} / \mathrm{ARBs}^{\mathrm{b}}{ }^{\mathrm{b}}$ usage & 0.7 & $0.6,0.9$ & 0.002 \\
$\mathrm{CPD}^{\mathrm{c}}$ & 1.6 & $1.3,1.9$ & $<0.001$ \\
$\mathrm{DM}^{\mathrm{e}}$ & 1.2 & $0.9,1.5$ & 0.077 \\
Malignancy & 2.2 & $1.3,3.6$ & 0.004 \\
Chronic use of immunosup- & 3.3 & $2.1,5.1$ & $<0.001$ \\
$\quad$ pressants & & & \\
Gender & 1.2 & $0.9,1.4$ & 0.069 \\
Age & $1.4^{\mathrm{f}}$ & $1.4,1.5$ & $<0.001$ \\
ICU $^{\epsilon}$ admission & 1.6 & $1.3,2.0$ & $<0.001$ \\
\hline
\end{tabular}

${ }^{a}$ Angiotensin-converting enzyme inhibitors

${ }^{\mathrm{b}}$ Angiotensin receptor blockers

${ }^{\mathrm{c}}$ Chronic pulmonary disease

${ }^{\mathrm{d}}$ Confidence interval

${ }^{\mathrm{e}}$ Diabetes mellitus, Intensive care unit

${ }^{\mathrm{f}}$ For every ten years increase

${ }^{€}$ Intensive care unit

${ }^{\pi}$ Hazard ratio
The beneficial effects of angiotensin (1-7) on the oxygenation, inflammatory cells infiltration, and fibrosis in an ARDS experimental model in the acute and late phases were demonstrated [22]. It is shown that angiotensin (1-7) has a protective role against inflammation, while angiotensin II is increased as a result of ACE2 downregulation and causes deleterious inflammatory effects in lung and is not inhibited by any of the ACEIs [23].

Furthermore, angiotensin (1-7) is produced by ACE2 with angiotensin II as a substrate, or due to angiotensin (1-9) metabolism by ACE1. Thus, under certain conditions and depending on the enzymes and substrates' local concentrations, the RAS might favor angiotensin (1-7) rather than angiotensin II production, and ultimately vasodilator effects will be dominant [24].

It was demonstrated that Lisinopril and Losartan caused the upregulation of ACE2 in animal models by 5 and 3 times, respectively. They also increased cardiac ACE2 gene expression and angiotensin (1-7)'s plasma levels [25].

A study with a small sample size suggested that ACEIs/ ARBs can improve the clinical outcome of COVID-19 patients with HTN [26]. The results of our study demonstrate 
Fig. 1 The survival curve of angiotensin-converting enzyme inhibitors or angiotensin receptor blockers receivers and non-receivers. Angiotensinconverting enzyme inhibitors or angiotensin receptor blockers

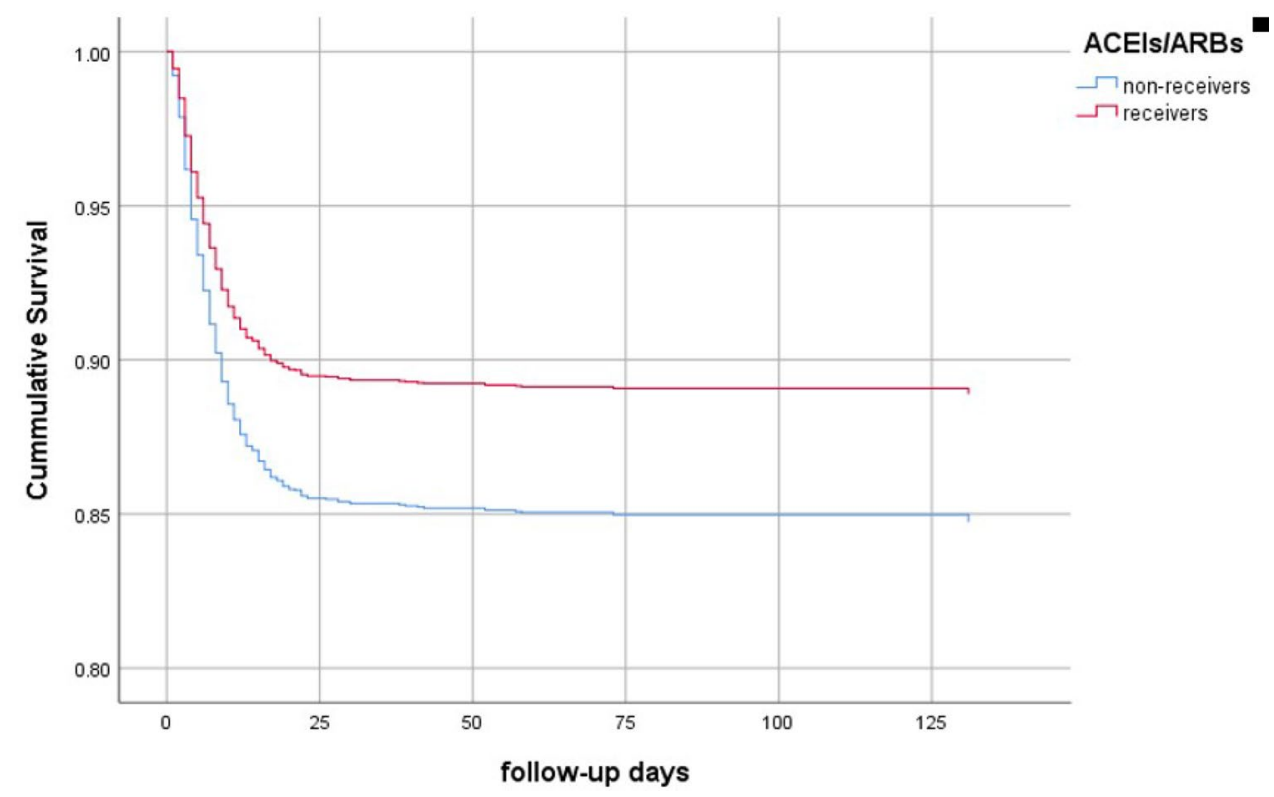

that by adjusting for underlying diseases, ICU admission, and demographic characteristics, medications that affect the RAS system (ACEIs and ARBs) became protective factors of mortality. It is claimed that ACE2 expression in patients who have not yet encountered the virus can increase the chance of developing a high viral load and getting a severe form of COVID-19. Once the viral load reaches its maximum amount, the primary cause leading to the deterioration of the clinical condition is the inflammatory response rather than the virus's effect. Here, one can deduce the administration of ACEI/ARBs with the mechanisms mentioned earlier can attenuate the inflammatory condition, therefore, decrease the severity of the disease [27]. This would further support our hypothesis that when the disease has progressed to the symptomatic stage, the administration of ACEIs/ ARBs will be protective.

We also investigated CCBs, diuretics, and beta-blockers in the same logistic regression model. Although the ORs decreased, their values remained higher than one and statistically not significant. Although it has been shown that betablockers can decrease secretion of renin, evidence claims that beta-blockers do not change the level of ACE2 expression [28]. The mechanisms of downregulation of ACE2 enzyme by SARS-CoV2 and the absence of upregulating effects of beta-blockers seem to be the reason behind their insignificant role in COVID-19 patients' survival. Diuretics increase the renin secretion through multiple mechanisms, but they may not affect the imbalance of ACE2 expression induced by SARS-CoV2. Therefore, the protective effects of ACEIs/ARBs cannot be observed by diuretics.

ACEIs receivers had higher rates of underlying conditions and higher age, LOS, and ICU admission. Although these rates were higher, all except LOS shown to be independent risk factors of mortality in COVID-19 patients, the mortality rate of ACEIs receivers did not differ with non-receivers when excluding patients who received ARBs. The same could be applied for ARBs when ACEIs receivers were excluded except for the unadjusted mortality rate, which is higher in ARBs receivers. The differences between only ACEIs and only ARBs receivers might be due to the smaller number of patients who received ACEIs in total. By increasing the number of patients who take ACEIs, one must expect a statistically significant difference in mortality. Although both of these medications increase the expression of ACE2, ACEIs only block ACE1 while ARBs block the ultimate receptor of angiotensin II. Another reason for the observed difference could be the different mechanisms of these agents' actions, which require further investigations. Ultimately, ACEIs/ARBs receivers were found to have a better survival probability.

Considering that ACEIs/ARBs are preferred blood pressure regulators in patients with a history of DM, CKD, and CVD [29, 30], these variables' confounding effects on ACEIs/ARBs administration can be explained. On the other hand, ICU admission as an indicator of the disease's severity is a significant risk factor of mortality, which also explains its confounding effects in the model.

Administration of ACEIs/ARBs was shown to be a protective factor $(\mathrm{OR}=0.3)$ although it was not statistically significant, probably due to the sample size being small, in a recent study by Yang et al. [31] In another study by Peng Zhang et al., in-hospital administration of ACEIs/ARBs in patients with concurrent HTN and COVID-19 was found to lower mortality risk in these cases (hazard ratio $=0.4$ ) [32]. Our findings are also in accordance with the results 
of these mentioned studies, which suggest ACEIs/ARBs as potential therapeutic options in all COVID-19 patients.

From the beginning of the outbreak, some studies performed survival analyses on COVID-19 patients. A recent Brazilian study calculated these patients' overall survival to be approximately $90 \%$ [33]. An international study also calculated the overall survival of the patients at around $70 \%$ [34]. Another study reported the overall survival of the Hispanic, African American, and white COVID-19 patients to be around $90 \%, 85 \%$, and $65 \%$, respectively [35]. In all these studies, the Kaplan-Meier curves reach a plateau state around the 20th to 30th day. The same could be observed in our study results in which the plateau is seen on the 25th day. It could be claimed that the probability of death becomes less likely after 20-30 days from hospitalization by receiving standard treatment.

Underlying diseases play an essential role in COVID-19 deleterious outcomes. Studies in China, Italy, and Singapore revealed that the prevalence of HTN, DM, CVD, chronic obstructive pulmonary disease (COPD), and CKD among COVID-19 patients was approximately $21 \%, 12 \%, 10 \%, 2 \%$, and $1 \%$, respectively [26]. The rate of underlying diseases is higher in the current study. This difference could be associated with the case selection method since only hospitalized patients were included. Hospitalization policies of included healthcare facilities consisted of selecting patients with more severe clinical conditions. This can explain relatively higher rates of CKD and CPD in this study. Age distribution pattern and overall frequency of underlying diseases in Iran compared with the other countries [36] could also account for the difference found between this study and the others. However, the reported rate of underlying diseases in this study is not the highest. For instance, CVD and DM rates in an Italian study were $42.5 \%$ and $35.5 \%$ [37].

In the case of CKD, studies in China showed no significant difference in the severity of illness between patients with and without a CKD history [38]. A meta-analysis on these studies reported that the pooled ORs of CKD are statistically significant and suggests that CKD can be a potential risk factor. Although there was no statistically significant difference in mortality of patients with and without a CKD history, the observation showed that the death rate in patients with CKD was higher (11.7\% vs $8.5 \%)$. It should also be noted that the mentioned meta-analysis had its limitations, such as small sample size in included studies [39].

AR calculates the number of infected cases among the exposed group that can be removed if the exposure is removed. It is impossible to calculate AR in most case-control studies because the incidence cannot be determined since participants are selected based on the disease. In this instance, the OR approximates the relative risk. Most of the recent studies have reported ORs regarding underlying diseases in COVID-19 patients.
In a meta-analysis of Chinese studies, HTN (pooled $\mathrm{OR}=2.3,95 \%$ CI $1.4,3.8$ ), $\mathrm{CPD}$ (pooled $\mathrm{OR}=2.4,95 \%$ CI $1.7,3.4$ ), and CVD (pooled OR $=3.4,95 \%$ CI $1.8,6.2$ ) were observed to be risk factors of mortality in COVID19 patients which are relatively close to what the results of this study shows [39]. As apparent in our results, one could observe dramatic changes in indices, such as OR after adjustment. For instance, in a study by Zhou et al., HTN, CAD, and DM were identified as significant risk factors of mortality in COVID-19 patients with ORs of 3.0, 21.4, 2.85, respectively. CPD was not a significant risk factor of mortality $(\mathrm{OR}=5.4,95 \%$ CI $0.9,30.4)$, and only CAD was adjusted in the regression model. After the adjustment, the OR of CAD changed drastically to 2.1 [40]. We suggest that future studies consider prospective designs to report risk and OR, although all indices have their advantages.

The chronic use of immunosuppressant medications had the highest AR between all underlying conditions. However, it had a relatively wide confidence interval, probably due to the small sample size. All underlying diseases proved to have positive ARs in this study. To the best of authors' knowledge, no study has calculated the ARs of each underlying disease in COVID-19 patients. We could not find any studies which consider the chronic use of immunosuppressants in COVID-19 patients.

Nevertheless, in a study by the Korean Society of Infectious Diseases and Korea Centers for Disease Control and Prevention, $14.8 \%$ of deceased patients were immune-compromised [41]. The authors considered patients suffering from malignancies and transplantation as immune-compromised. With the same definition of immune-compromised patients, the mortality rate in our study was $7.5 \%$. The advantage of the definition provided in our study is that it is considering all possible situations that a patient could be considered immunocompromised. The difference in rates between our study and the Korean one could be attributed to their small sample size. We suggest that future studies be designed with proper sample size, control group, and subgroups of immune-compromising etiologies.

The database we used consisted of information gathered from 17 major hospitals of a highly populated city covering 5.3 million people. This database updates in real-time, and it is accurate and consistent because the least amount of human error is involved in the data entry process. As far as we investigated the literature, this study has the largest sample size regarding this matter up to now. This study also included anti-HTN medications other than ACEIs/ARBs to compare their effects on mortality. As a secondary goal, we also calculated ARs of some frequent underlying diseases. Considering that all of our patients were admitted to the hospital and had moderate to severe clinical conditions, calculated ARs might be higher than overall ARs in the general 
population. Therefore, these findings should be generalized to the population of the COVID-19 patients with caution.

The obtained results and the previously published evidence [42] suggest that patients who are under treatment with ACEIs/ARBs should continue taking their medications; but deciding whether to initiate administration of these agents in COVID-19 patients, needs many further investigations in the form of randomized clinical trials. As for the first mechanism of action for ACEIs/ARBs, clinical trials are currently investigating the use of human recombinant ACE2 (hr-ACE2) as a novel therapeutic option for COVID-19 [43].

\section{Limitations}

This study's limitations were that the grade of HTN and the duration of ACEIs/ARBs administration were unknown. The design was a retrospective cohort and for a definite answer to this debate designing randomized clinical trials that consider variables mentioned in this article is crucial.

\section{Conclusion}

Administration of ACEIs/ARBs in COVID-19 patients with concurrent HTN will result in improved clinical outcomes, and these medications can be potential therapeutic options and increase the survival probability in these cases. Other anti-HTN medications did not have a protective effect on mortality. Furthermore, COVID-19 patients with a history of chronic immunosuppressant administration, malignancy, CPD, CVD, DM, HTN, and CKD were found to have an increased risk of mortality.

Acknowledgements We thank Dr. Seyed Mohammad Tabatabayi, Dr. Ehsan Bitaraf, all front line healthcare professionals who are currently working against the COVID-19 outbreak in Iran University of Medical Sciences, Tehran, Iran, and people who helped us in the process of data extraction.

\section{Compliance with ethical standards}

Conflict of interests The authors declared no conflict of interest.

Statement of human and animal rights This study has been confirmed and granted by IRB of Iran University of Medical Sciences, Tehran, Iran with this number 99-1-39-17695. Ethics committee has also confirmed the research proposal by this code: IR.IUMS.REC.1399.200.

Informed consent All cases has signed an informed consent to use their data for research purposes at the registration time in each hospital.

\section{References}

1. World Health Organization (2020) Coronavirus disease (COVID19): weekly epidemiological update. https://www.who.int/docs/ default-source/coronaviruse/situation-reports/20200921-week1 y-epi-update-6.pdf?sfvrsn=d9cf9496_6. Accessed 22 Sept 2020

2. Huang C, Wang Y, Li X, Ren L, Zhao J, Hu Y, Zhang L, Fan G, Xu J, Gu X, Cheng Z, Yu T, Xia J, Wei Y, Wu W, Xie X, Yin W, Li H, Liu M, Xiao Y, Gao H, Guo L, Xie J, Wang G, Jiang R, Gao Z, Jin Q, Wang J, Cao B (2020) Clinical features of patients infected with 2019 novel coronavirus in Wuhan, China. Lancet (Lond Engl) 395(10223):497-506. https://doi.org/10.1016/s0140 $-6736(20) 30183-5$

3. Wang D, Hu B, Hu C, Zhu F, Liu X, Zhang J, Wang B, Xiang H, Cheng Z, Xiong Y, Zhao Y, Li Y, Wang X, Peng Z (2020) Clinical characteristics of 138 hospitalized patients with 2019 novel coronavirus-infected pneumonia in Wuhan China. JAMA 323(11):1061-1069. https://doi.org/10.1001/jama.2020.1585

4. Li G, De Clercq E (2020) Therapeutic options for the 2019 novel coronavirus (2019-nCoV). Nat Rev Drug Discovery 19(3):149_ 150. https://doi.org/10.1038/d41573-020-00016-0

5. Vaduganathan M, Vardeny O, Michel T, McMurray JJV (2020) Renin-angiotensin-aldosterone system inhibitors in patients with covid-19. N Engl J Med 382 (17):1653-1659. https://doi. org/10.1056/NEJMsr2005760

6. Xu X, Chen P, Wang J, Feng J, Zhou H, Li X, Zhong W, Hao $P$ (2020) Evolution of the novel coronavirus from the ongoing Wuhan outbreak and modeling of its spike protein for risk of human transmission. Sci China Life Sci 63(3):457-460. https:// doi.org/10.1007/s11427-020-1637-5

7. Li F, Li W, Farzan M, Harrison SC (2005) Structure of SARS coronavirus spike receptor-binding domain complexed with receptor. Sci (New York, NY) 309(5742):1864-1868. https://doi. org/10.1126/science. 1116480

8. Zhang H, Penninger JM, Li Y, Zhong N, Slutsky AS (2020) Angiotensin-converting enzyme 2 (ACE2) as a SARS-CoV-2 receptor: molecular mechanisms and potential therapeutic target. Intensive Care Med 46(4):586-590. https://doi.org/10.1007/s00134-02005985-9

9. Sun ML, Yang JM, Sun YP, Su GH (2020) [Inhibitors of RAS might be a good choice for the therapy of COVID-19 Pneumonia]. Zhonghua jie he he hu xi za zhi = Zhonghua jiehe he huxi zazhi. Chinese J Tubercul Respir Dis 43(3):219-222. https://doi. org/10.3760/cma.j.issn.1001-0939.2020.03.016

10. Turner AJ, Hiscox JA, Hooper NM (2004) ACE2: from vasopeptidase to SARS virus receptor. Trends Pharmacol Sci 25(6):291294. https://doi.org/10.1016/j.tips.2004.04.001

11. Albini A, Di Guardo G, Noonan DM, Lombardo M (2020) The SARS-CoV-2 receptor, ACE-2, is expressed on many different cell types: implications for ACE-inhibitor- and angiotensin II receptor blocker-based cardiovascular therapies. Intern Emerg Med 15(5):759-766. https://doi.org/10.1007/s11739-020-02364-6

12. Li LQ, Huang T (2020) COVID-19 patients' clinical characteristics, discharge rate, and fatality rate of meta-analysis. J Med Virol 92 (6):577-583. https://doi.org/10.1002/jmv.25757

13. Chen C, Zhou Y, Wang DW (2020) SARS-CoV-2: a potential novel etiology of fulminant myocarditis. Herz 45(3):230-232. https://doi.org/10.1007/s00059-020-04909-z

14. Moon JY (2013) Recent update of renin-angiotensin-aldosterone system in the pathogenesis of hypertension. Elect Blood Press E BP 11(2):41-45. https://doi.org/10.5049/ebp.2013.11.2.41

15. World Health Organization (2020) Clinical management of severe acute respiratory infection (SARI) when COVID-19 disease is suspected: interim guidance, 13 March 2020. World Health Organization. https://www.who.int/docs/default-source/coronaviruse/situa 
tion-reports/20200921-weekly-epi-update-6.pdf?sfvrsn=d9cf9 496 6. Accessed 4 April 2020

16. Riazi H, Jafarpour M, Bitaraf E (2014) Towards National eHealth Implementation-a comparative study on WHO/ITU National eHealth Strategy Toolkit in Iran. Stud Health Technol Informat 205:246-250

17. Iranian national scientific committee of COVID-19 managment (2020) Iraninan national guideline for diagnosis and treatment of COVID-19 in outpatient and inpatient settings No.5. https:// firoozgar.iums.ac.ir/files/baharestan/files/n5.pdf. Accessed 18 Mar 2020

18. Fang L, Karakiulakis G, Roth M (2020) Are patients with hypertension and diabetes mellitus at increased risk for COVID-19 infection? Lancet Respir Med 8(4):e21. https://doi.org/10.1016/ s2213-2600(20)30116-8

19. Yan T, Xiao R, Lin G (2020) Angiotensin-converting enzyme 2 in severe acute respiratory syndrome coronavirus and SARS-CoV-2: a double-edged sword? FASEB J Off Publ Feder Am Soc Exp Biol 34(5):6017-6026. https://doi.org/10.1096/fj.202000782

20. Kuba K, Imai Y, Rao S, Gao H, Guo F, Guan B, Huan Y, Yang P, Zhang Y, Deng W, Bao L, Zhang B, Liu G, Wang Z, Chappell M, Liu Y, Zheng D, Leibbrandt A, Wada T, Slutsky AS, Liu D, Qin C, Jiang C, Penninger JM (2005) A crucial role of angiotensin converting enzyme 2 (ACE2) in SARS coronavirus-induced lung injury. Nat Med 11(8):875-879. https://doi.org/10.1038/nm1267

21. Patel AB, Verma A (2020) COVID-19 and angiotensin-converting enzyme inhibitors and angiotensin receptor blockers: what is the evidence? JAMA 323(18):1769-1770. https://doi.org/10.1001/ jama.2020.4812

22. Zambelli V, Bellani G, Borsa R, Pozzi F, Grassi A, Scanziani M, Castiglioni V, Masson S, Decio A, Laffey JG, Latini R, Pesenti A (2015) Angiotensin-(1-7) improves oxygenation, while reducing cellular infiltrate and fibrosis in experimental acute respiratory distress syndrome. Intensive Care Med Exp 3(1):44. https://doi. org/10.1186/s40635-015-0044-3

23. Guy JL, Jackson RM, Acharya KR, Sturrock ED, Hooper NM, Turner AJ (2003) Angiotensin-converting enzyme-2 (ACE2): comparative modeling of the active site, specificity requirements, and chloride dependence. Biochemistry 42(45):13185-13192. https://doi.org/10.1021/bi035268s

24. Rice GI, Thomas DA, Grant PJ, Turner AJ, Hooper NM (2004) Evaluation of angiotensin-converting enzyme (ACE), its homologue ACE2 and neprilysin in angiotensin peptide metabolism. Biochem J 383(Pt 1):45-51. https://doi.org/10.1042/bj20040634

25. Ferrario CM, Jessup J, Chappell MC, Averill DB, Brosnihan KB, Tallant EA, Diz DI, Gallagher PE (2005) Effect of angiotensin-converting enzyme inhibition and angiotensin II receptor blockers on cardiac angiotensin-converting enzyme 2. Circulation 111(20):2605-2610. https://doi.org/10.1161/circulatio naha.104.510461

26. Singh AK, Gupta R, Misra A (2020) Comorbidities in COVID-19: Outcomes in hypertensive cohort and controversies with renin angiotensin system blockers. Diab Metab Synd 14(4):283-287. https://doi.org/10.1016/j.dsx.2020.03.016

27. Meng J, Xiao G, Zhang J, He X, Ou M, Bi J, Yang R, Di W, Wang Z, Li Z, Gao H, Liu L, Zhang G (2020) Renin-angiotensin system inhibitors improve the clinical outcomes of COVID-19 patients with hypertension. Emerg Microbes Infect 9(1):757-760. https:// doi.org/10.1080/22221751.2020.1746200

28. Wang Y, Moreira Mda C, Heringer-Walther S, Schultheiss HP, Siems WE, Wessel N, Walther T (2015) Beta blockers prevent correlation of plasma ACE2 activity with echocardiographic parameters in patients with idiopathic dilated cardiomyopathy. J Cardiovasc Pharmacol 65(1):8-12. https://doi.org/10.1097/ fjc. 0000000000000156
29. Hao G, Wang Z, Guo R, Chen Z, Wang X, Zhang L, Li W (2014) Effects of ACEI/ARB in hypertensive patients with type 2 diabetes mellitus: a meta-analysis of randomized controlled studies. BMC Cardiovasc Disord 14:148. https://doi. org/10.1186/1471-2261-14-148

30. Hilgers KF, Dötsch J, Rascher W, Mann JF (2004) Treatment strategies in patients with chronic renal disease: ACE inhibitors, angiotensin receptor antagonists, or both? Pediat Nephrol (Berlin Ger) 19(9):956-961. https://doi.org/10.1007/s00467-004-1554-5

31. Yang G, Tan Z, Zhou L, Yang M, Peng L, Liu J, Cai J, Yang R, Han J, Huang Y, He S (2020) Effects of angiotensin II receptor blockers and ACE (angiotensin-converting enzyme) inhibitors on virus infection, inflammatory status, and clinical outcomes in patients with COVID-19 and hypertension: a single-center retrospective study. Hypertens (Dallas, Tex 1979) 76(1):51-58. https ://doi.org/10.1161/hypertensionaha.120.15143

32. Zhang P, Zhu L, Cai J, Lei F, Qin JJ, Xie J, Liu YM, Zhao YC, Huang X, Lin L, Xia M, Chen MM, Cheng X, Zhang X, Guo D, Peng Y, Ji YX, Chen J, She ZG, Wang Y, Xu Q, Tan R, Wang H, Lin J, Luo P, Fu S, Cai H, Ye P, Xiao B, Mao W, Liu L, Yan Y, Liu M, Chen M, Zhang XJ, Wang X, Touyz RM, Xia J, Zhang BH, Huang X, Yuan Y, Loomba R, Liu PP, Li H (2020) Association of inpatient use of angiotensin-converting enzyme inhibitors and angiotensin II receptor blockers with mortality among patients with hypertension hospitalized with COVID-19. Circ Res 126(12):1671-1681. https://doi.org/10.1161/circresaha.120.31713 4

33. Sousa GJB, Garces TS (2020) Mortality and survival of COVID19. Epidemiol Infect 148:e123. https://doi.org/10.1017/s0950 268820001405

34. Beigel JH, Tomashek KM, Dodd LE, Mehta AK, Zingman BS, Kalil AC (2020) Remdesivir for the treatment of Covid-19. Prelim Rep. https://doi.org/10.1056/NEJMoa2007764

35. Price CC, Altice FL, Shyr Y, Koff A, Pischel L, Goshua G, Azar MM, McManus D, Chen SC, Gleeson SE, Britto CJ, Azmy V, Kaman K, Gaston DC, Davis M, Burrello T, Harris Z, Villanueva MS, Aoun-Barakat L, Kang I, Seropian S, Chupp G, Bucala R, Kaminski N, Lee AI, LoRusso PM, Topal JE, Dela Cruz C, Malinis M (2020) Tocilizumab treatment for cytokine release syndrome in hospitalized COVID-19 patients: survival and clinical outcomes. Chest. https://doi.org/10.1016/j.chest.2020.06.006

36. Institute for health Metrics and Evaluation (IHME) (2015) global burden of diseases compare, Seattle, WA: IHME,University of Washington. https://vizhub.healthdata.org/gbd-compare

37. Onder G, Rezza G, Brusaferro S (2020) Case-fatality rate and characteristics of patients dying in relation to COVID-19 in Italy. JAMA 323(18):1775-1776. https://doi.org/10.1001/ jama.2020.4683

38. Henry BM, Lippi G (2020) Chronic kidney disease is associated with severe coronavirus disease 2019 (COVID-19) infection. Int Urol Nephrol 52(6):1193-1194. https://doi.org/10.1007/s1125 5-020-02451-9

39. Hu Y, Sun J, Dai Z, Deng H, Li X, Huang Q, Wu Y, Sun L, Xu Y (2020) Prevalence and severity of corona virus disease 2019 (COVID-19): A systematic review and meta-analysis. J Clin Virol Off Publi Pan Am Soc Clin Virol 127:104371. https://doi. org/10.1016/j.jcv.2020.104371

40. Zhou F, Yu T, Du R, Fan G, Liu Y, Liu Z, Xiang J, Wang Y, Song B, Gu X, Guan L, Wei Y, Li H, Wu X, Xu J, Tu S, Zhang Y, Chen $\mathrm{H}$, Cao B (2020) Clinical course and risk factors for mortality of adult inpatients with COVID-19 in Wuhan, China: a retrospective cohort study. Lancet (Lond Engl) 395(10229):1054-1062. https:// doi.org/10.1016/s0140-6736(20)30566-3

41. Analysis on 54 mortality cases of coronavirus disease (2019) in the Republic of Korea from January 19 to March 10, 2020 
(2020). J Korean Med Sci 35(12):e132. https://doi.org/10.3346/ jkms.2020.35.e132

42. Sarzani R, Giulietti F, Di Pentima C, Filipponi A, Spannella F (2020) Antagonizing the renin-angiotensin-aldosterone system in the era of COVID-19. Intern Emerg Med 15(5):885-887. https:// doi.org/10.1007/s11739-020-02365-5

43. Monteil V, Kwon H, Prado P, Hagelkrüys A, Wimmer RA, Stahl M, Leopoldi A, Garreta E, Hurtado Del Pozo C, Prosper F, Romero JP, Wirnsberger G, Zhang H, Slutsky AS, Conder R, Montserrat N, Mirazimi A, Penninger JM (2020) Inhibition of
SARS-CoV-2 infections in engineered human tissues using clinical-grade soluble human ACE2. Cell 181(4):905-913.e907. https ://doi.org/10.1016/j.cell.2020.04.004

Publisher's Note Springer Nature remains neutral with regard to jurisdictional claims in published maps and institutional affiliations. 